\title{
LAS UNIVERSIDADES LABORALES DE LUIS LAORGA Y JOSÉ LÓPEZ ZANÓN: ESTUDIOS SOBRE EL MÓDULO
}

\author{
Pablo Basterra Ederra
}

Dentro de la amplia variedad de planteamientos conceptuales, constructivos y estilísticos adoptados por los diferentes arquitectos autores de las veintiuna Universidades Laborales españolas, el presente artículo se centra en las proyectadas por Luis Laorga y José López Zanón y, más concretamente, en sus propuestas y avances en la búsqueda de una arquitectura modular como idea generadora del conjunto.

Palabras clave: Arquitectura, España, siglo XX, módulo, Laorga, López Zanón Keywords: Architecture, Spain, 20th century, unit, Laorga, López Zanón

A principios de los años cincuenta se comienza a desarrollar en España una red de centros docentes (que sólo a partir de 1959 se comenzarían a llamar U niversidades L aborales) distribuidos por todo el país, con la voluntad de formar a los hijos de la clase obrera y capacitarlos para disponer de mano de obra cualificada. Después de una década de regreso a la economía agraria, en los años cuarenta, el país debía recuperar su tejido industrial y, para ello, necesitaba trabajadores preparados. Se plantearon para ello unos grandes complejos educativos que, lejos de ser simples centros docentes al uso, fueron concebidos como verdaderas ciudades, con residencias, comedores, talleres, pistas deportivas, gimnasios, capillas y todas aquellas dependencias que fuesen necesarias para el desarrollo completo del alumno.

Estos centros fueron promovidos por el Ministerio de Trabajo y, aunque muchos de ellos se adjudicaron como encargo directo, otras se resolvieron mediante la convocatoria de un concurso de arquitectura. Tal es el caso de la U niversidad L aboral de Coruña, que se convocó en el año 1960 (B OE de 19 de abril, p. 5124), que fue ganado por los arquitectos L uis L aorga y José López Zanón. Estos mismos arquitectos ganaron dos años más tarde el concurso para la U niversidad Laboral de M adrid, que finalmente no llegó a construirse; como desagravio, en el año 1965 les encargarían los proyectos para las U niversidades L aborales de Huesca y Cáceres ${ }^{1}$.

En su desconocimiento de que el origen de las Universidades Laborales provenía de B élgica, y dada su cercanía con la cultura norteamericana (habían construido las viviendas para los M ilitares A mericanos - ochocientas sesenta y seis en M adrid y doscientas sesenta y seis en Zaragoza- entre los años 1955 y 1958, para lo cual habían entrado en contacto con algunos arquitectos norteamericanos, como el consultor E.J. K ump), Laorga y López Zanón volvieron la mirada hacia las High School y las arquitecturas del New Deal de los años cuarenta americanas. A demás, conocieron al gunos ejemplos norte-europeos de arquitectura docente y escolar, donde se venían realizando avances de acuerdo con las nuevas tendencias educativas, y entre cuyos maestros se encontraban arquitectos de la talla de A splund, Jacobsen $0 \mathrm{~A}$ al to.

\section{EL CONCURSO PARA LA UNIVERSIDAD LABORAL DE A CORUÑA}

El equipo de arquitectos formado por Luis Laorga y José $L$ ópez Zanón ganó en el año 1960 el concurso de anteproyectos para la U niversidad Laboral de La Coruña bajo el lema "M ar"2. El programa de necesidades dispuesto en las bases hacía referencia a un número superior a mil al umnos, compuesto en principio de ochocientos externos y trescientos internos, para equilibrarse por mitades en una segunda fase; es decir, ya desde el comienzo se plan-
1. De este modo, Laorga y López Zanón se convirtieron en el segundo equipo de arquitectos que más centros de este tipo construyeron, con tres (Huesca, La Coruña y Cáceres); por delante, Fernando Moreno-Barberá, con cuatro (Toledo, Málaga, Las Palmas y Cheste); por detrás, Julio Cano Lasso y Luis Moya Blanco, con dos Universidades Laborales cada uno (Almería y Ourense el primero y Zamora y Giijón el segundo).

2. Revista Arquitectura n. 31, 1961. El segundo premio fue para el arquitecto Luis Vázquez de Castro, y los accésit para el equipo de arquitectos formado por Joaquín Fiter Bilbao y Luis Mares Feliz; el equipo formado por P. Pintado y Biba, J. Bravo Giralt, R. Lozano Prieto y J. Navarro Gutiérrez; y un último accésit para el arquitecto Federico del Cerro. 
Fig. 1. Maqueta del concurso para la UL de A Coruña.

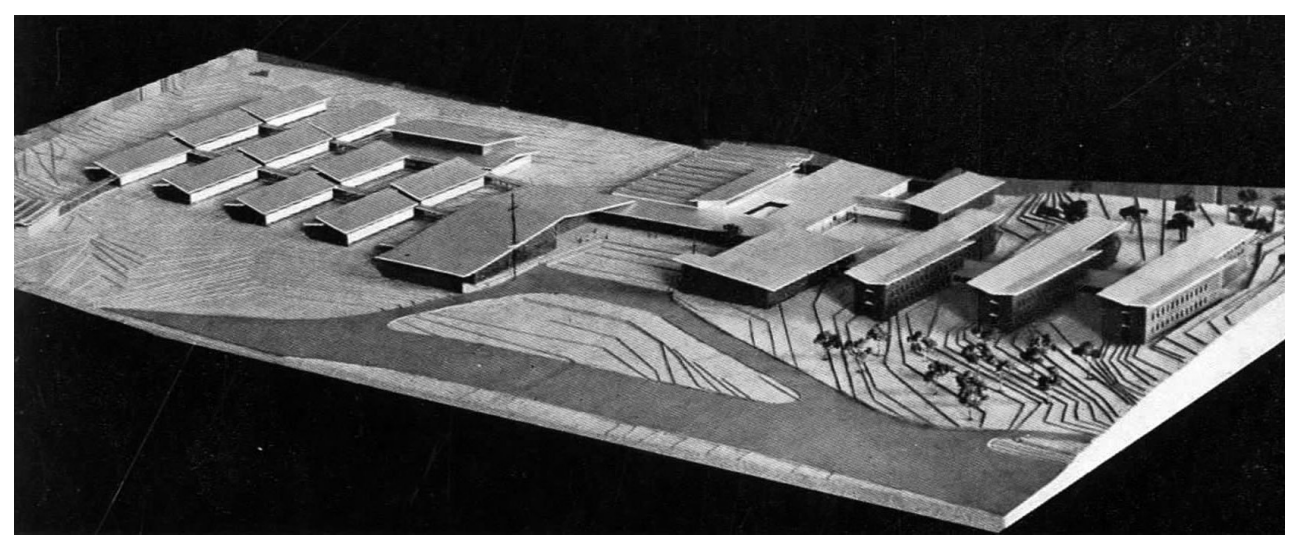

teaba la posibilidad, casi obligatoriedad, de diseñar un edificio o complejo de edificios que pudieran desarrollarse en varias fases sucesivas; esto planteaba una dificultad añadida, que no era baladí al afrontar la disposición de los diferentes usos del programa: los elementos comunes, situados en la parte central del proyecto, debían estar completos desde el inicio, por lo que el correcto dimensionamiento de los mismos se convertía en pieza clave de la propuesta. Otro tema, no menos importante, era la concepción del modo de crecimiento del edificio, que debía ser planteado desde el inicio y sería uno de los aspectos clave a valorar por el jurado.

El solar que se encontraron los arquitectos era una ladera extraordinariamente húmeda, con una suave pero continua pendiente hacia el Sur, y en ella se tenía que dar acomodo a un programa complejo educativo, residencial, deportivo y de servicios complementarios (algunos de ellos, como los talleres, con una dimensión muy importante). En la propuesta de L aorga y López Zanón, el conjunto se concibió como un desarrollo eminentemente horizontal en dos zonas claramente segregadas: por un lado, la zona docente, con predominio de la planta baja, y por el otro la zona de residencia, en la que destacan en altura los dormitorios de estudiantes, en pabellones de tres plantas, situados en la parte más alta del terreno. Los talleres se situaron en la zona más baja de la parcela, en la que su impacto visual fuese menor, y ajenos a la estructura general de la propuesta. Tanto es así que, en un inicio, fueron los únicos elementos que se salieron de la ortogonalidad de la malla generadora ${ }^{3}$.

Formalmente, la solución contaba con cubiertas a un agua de grandes dimensiones, jugando con los volúmenes y caídas de faldones, y todo ello plegado a la topografía. L os diferentes pabel lones quedaban unidos entre sí por galerías cubiertas, en un esquema en espina de pez. Este esquema, verdadero leit motiv del concurso, permitía un crecimiento natural de la propuesta, tanto hacia el norte con las aulas como hacia el sur con los elementos de residencia. Este hecho hacía que, además, el conjunto se reconociera con unidad, evitando la posible fragmentación en un esquema de este tipo.

El proyecto para la U niversidad Laboral de Coruña, si bien adelanta al gunos temas que serán recurrentes en el concurso de $M$ adrid ${ }^{4}$, no trabaja el tema del módulo sino en concepto; es decir, propone un sistema de crecimiento modular, ordenado y con una clara ley de desarrollo horizontal (no vertical, como se verá más adelante en Madrid), pero con unos el ementos que no son modulares en sí mismos. L os diferentes pabellones funcionan de forma autónoma, creando células que se van sumando por adición, mediante unas espinas de comunicaciones que los van enhebrando y haciendo que funcionen en conjunto.

\section{EL CONCURSO PARA LA UNIVERSIDAD LABORAL DE MADRID}

En el año 1962 se convocó un concurso nacional de Arquitectura para construir una U niversidad Laboral en M adrid. Era, por tanto, la primera de todas ellas que no se proyectaba para la periferia de la Península 5 . El primer premio fue otorgado a los arquitectos L uis Laorga y J osé López Zanón, el segundo recayó en L uis Vázquez de Castro ${ }^{6}$ y el tercero en el equipo formado por J osé R. A spiazu y Felipe Lafita. 

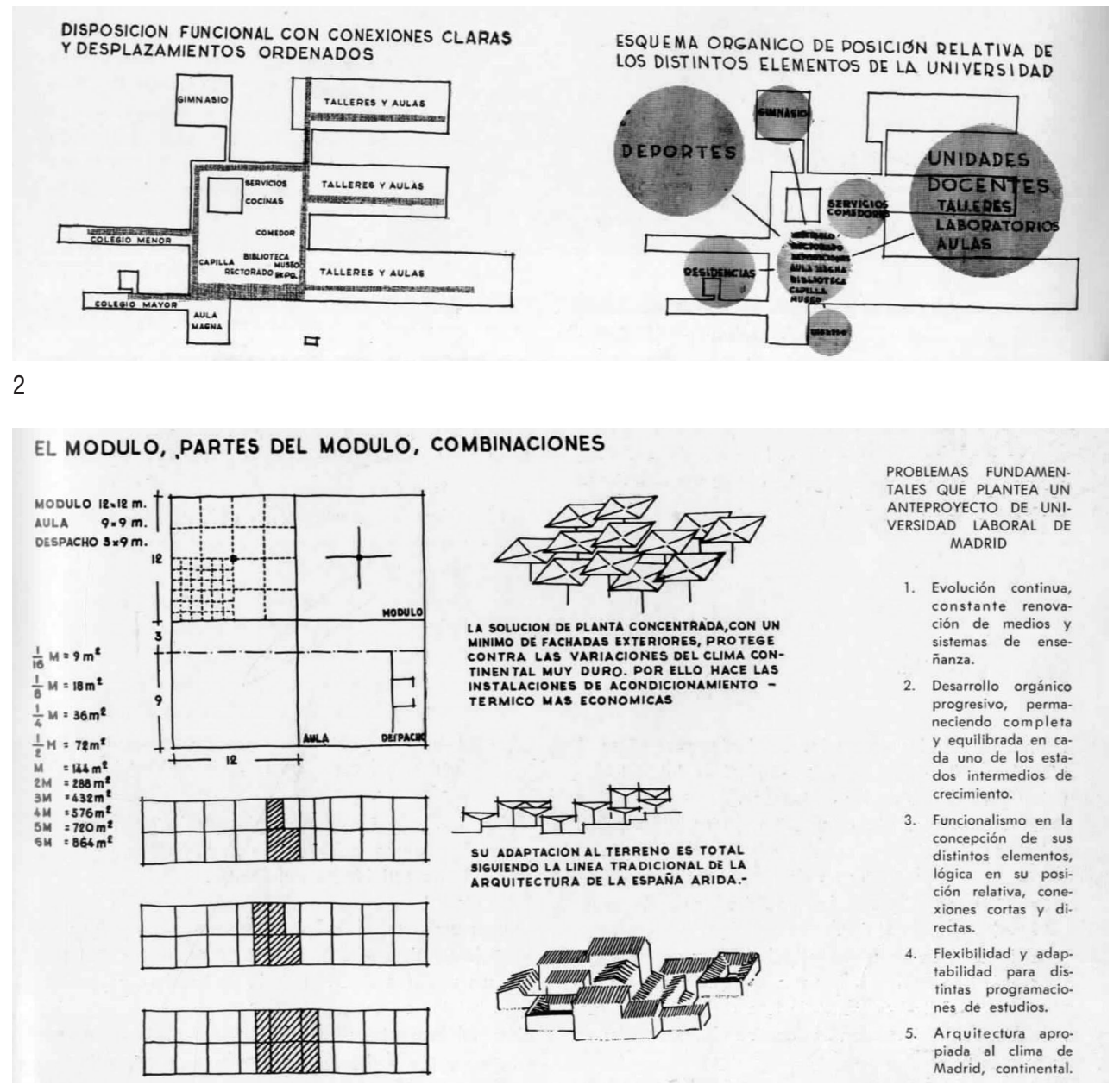

3

Las bases del concurso planteaban la necesidad de acoger a mil setecientos al umnos externos y trescientos en régimen de internado. La superficie construida total prevista era de treinta mil metros cuadrados, y el presupuesto alcanzaba los noventa y dos millones de pesetas de la época. L as premisas de partida eran las siguientes: la U niversidad estará en continua evolución, con una renovación constante de medios y sistemas; la Universidad ha de crecer de manera continua y orgánica, permaneciendo completa en cada uno de sus estados intermedios de crecimiento; tendrá una gran flexibilidad en cuanto a su funcionamiento.

Como respuesta, Laorga y López Zanón proyectaron un edificio completamente basado en el módulo, que respondía a las exigencias enunciadas; con ello, y según la publicación del concurso en la revista Arquitectura ${ }^{7}$, se conseguía:

a) Una disposición funcional de elementos, con conexiones claras entre ellos, esquema simple y movimientos ordenados.

b) La posibilidad de crecer paulatinamente, Ilegando por etapas completas hasta la fase prevista actualmente y pudiendo continuar su desarrollo orgánico, constituyendo en cada etapa parcial un conjunto cerrado y completo, desde el punto de vista funcional, arquitectónico y plástico.

c) Gran flexibilidad en su organización, ya que por adición de módulos se puede aumentar cualquier servicio en formas diversas.

d) Completa adaptación al terreno.

e) L a solución en planta concentrada con un mínimo de fachadas exteriores protege contra las variaciones del clima y hace las instalaciones más económicas.

f) El sistema adoptado permite la prefabricación en serie, con notable economía en el presupuesto y tiempo de ejecución.
Fig. 2. Esquemas publicados en la revista Arquitectura.

Fig. 3. Esquemas sobre el módulo, publicados en la revista Arquitectura. 
Fig. 4. Imagen de concurso. Perspectiva cónica.

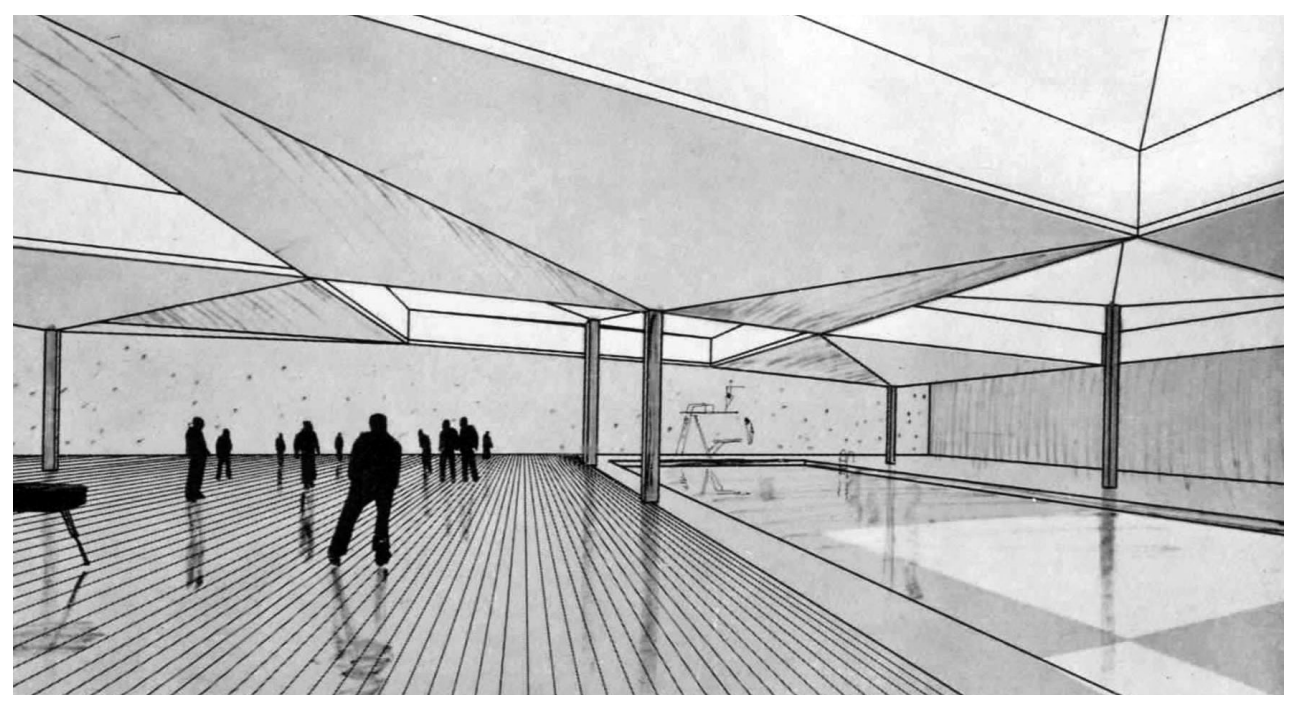

El módulo se materializaba en este caso en una seta de hormigón armado, que era el elemento fundamental del proyecto en cuanto a construcción y carácter. Este elemento estaba constituido por cuatro hojas de paraboloide hiperbólico acordadas entre sí, cubriendo una superficie cuadrada de doce metros de lado, con un solo soporte central. Este sistema permitía la aplicación de las incipientes técnicas de la prefabricación, dado que los soportes los podía suministrar la industria, y las setas ensamblarse sobre el suelo, a pie de obra, para ser el evadas y replanteadas por medio de grúas.

La colocación en damero de las setas, con diferencias de altura de un metro entre sus bordes, generaba líneas continuas de cuarenta y ocho metros cuadrados de ventana para ventilación e iluminación, que representaba un veinte por ciento aproximadamente de la superficie cubierta. Este recurso producía un adecuado nivel de iluminación, razonablemente uniforme, y conseguía que no hubiese ninguna zona interior desde la que el usuario no viese el cielo. Este sistema de disposición agrupada en planta permitía además que, al concentrar módulos, se acortasen los recorridos, tanto en desplazamientos de personas como en trazados de instalaciones.

Una vez definido este módulo estructural y de cerramiento, la parte más sensible podía ser la disposición de las tabiquerías interiores para la generación de los diferentes tipos de espacios. La solución adoptada por los arquitectos pasaba por el planteamiento de una serie de mamparas móviles, de tal forma que se adaptasen fácilmente a cualquier cambio en la distribución del programa, al mismo tiempo que garantizaban una flexibilidad inmediata de los espacios, cuestión esta que enlazaba perfectamente con la concepción modular del proyecto.

Las bases del concurso planteaban que, en cada etapa parcial de desarrollo, se constituyese un conjunto completo y cerrado desde el punto de vista arquitectónico, funcional y plástico. Los arquitectos propusieron, mediante dibujos esquemáticos sucesivos, una suerte de Plan Director de desarrollo de las instalaciones. En estos esquemas se iba completando la trama modular, tanto en extensión como en altura, manteniendo en todo momento la coherencia y unidad del conjunto, así como la escala humana del mismo, al go que preocupó a los autores desde el inicio.

El cuidado estudio del módulo, unido a la zonificación de espacios por usos, contribuían a la clarificación conceptual y al buen uso del edificio; además, la unidad del conjunto permitía poner en práctica la filosofía de los arquitectos en relación con la universalidad de los conocimientos.

Según Laorga y López Zanón, los principales problemas que planteaba el anteproyecto para la U niversidad L aboral de M adrid eran los siguientes: 1. Evolución continua, constante renovación de medios y sistemas de enseñanza. 2. Desarrollo orgánico progresivo, perma- 


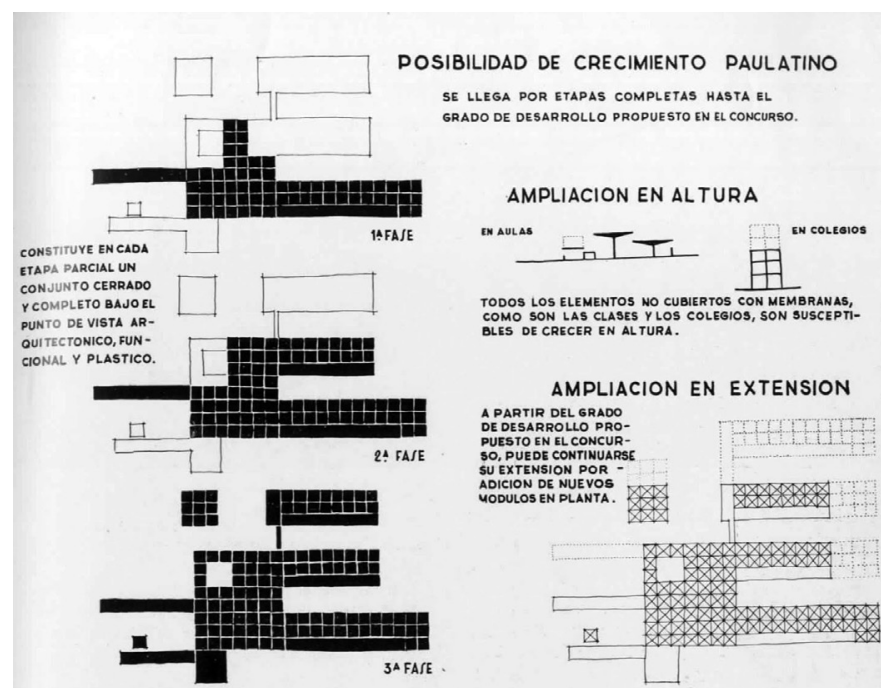

5

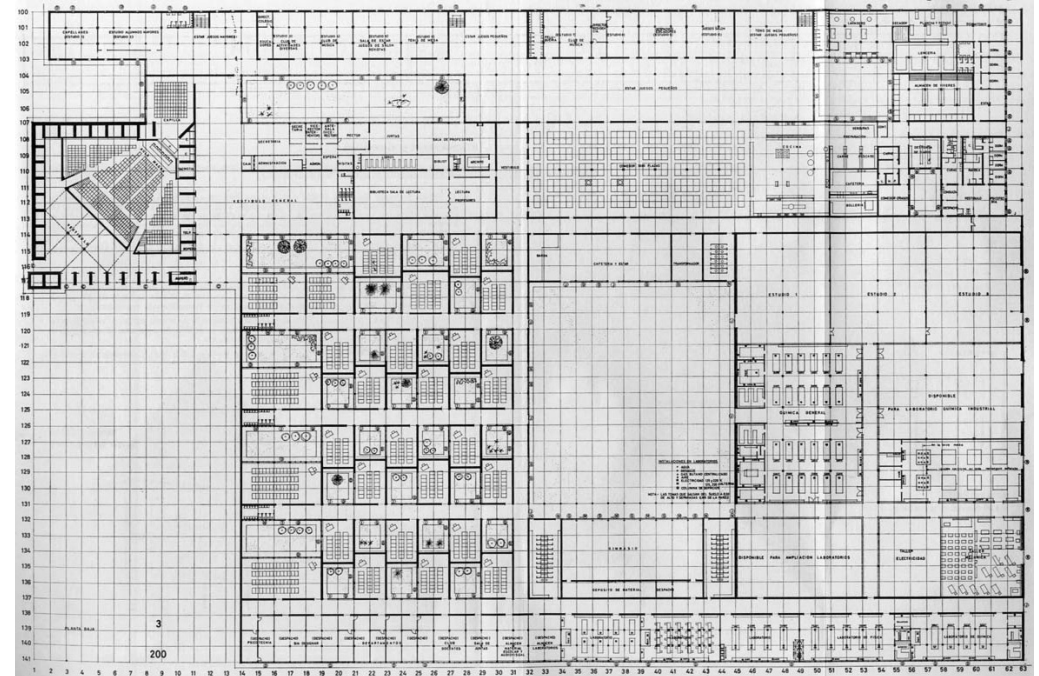

6 neciendo completa y equilibrada en cada uno de los estados intermedios de crecimiento. 3. Funcionalismo en la concepción de sus distintos elementos, lógica en su posición relativa, conexiones cortas y directas. 4. Flexibilidad y adaptabilidad para distintas programaciones de estudios. 5. A rquitectura apropiada al clima de M adrid, continental.

Finalmente, la Universidad Laboral de M adrid no llegó a construirse ${ }^{8}$, debido a problemas políticos y presupuestarios. En desagravio, a los arquitectos ganadores del concurso se les adjudicaron los proyectos para las Universidades L aborales de Huesca y Cáceres, algunos años después, en los que siguieron estudiando y poniendo en práctica las diferentes posibilidades de la arquitectura modular que marcaron parte de su investigación en el campo de la edificación.

\section{LAS UNIVERSIDADES LABORALES DE HUESCA Y CÁCERES}

Como en el resto de U niversidades Laborales españolas, los programas de necesidades para las de Huesca y Cáceres incluían un conjunto de dotaciones encaminado a facilitar al alumno las mejores y más completas instalaciones donde desarrollarse en todos los aspectos: educativo, social, deportivo y humano.

En Huesca, el edificio fue previsto en origen para mil quinientos al umnos, dos tercios de los cual es estarían en régimen de residencia o internado. Para ello, el programa de necesidades referente a un centro que diese cabida a un al umnado heterogéneo y tan numeroso incluía aulas, laboratorios, talleres, zona de dirección y administración, residencia para todos los alumnos internos y profesores, zona de comedores y un salón de actos con cabida para mil cien personas, que se convertiría a lo largo de los años en auditorio y sala para conferencias de referencia no solo para la propia U niversidad L aboral, sino para toda H uesca, debido a su considerable aforo y su impecable acústica.

La primera decisión que tomaron Laorga y López Zanón fue la de resolver todo el programa de necesidades en un solo edificio. Por tanto, la disposición del complejo en planta es compacta, de acuerdo con la idea que habían venido trabajando los arquitectos durante años de que los edificios universitarios (aún a sabiendas de que una U niversidad L aboral no lo era) debían estar agrupados para facilitar el intercambio de información y la difusión del saber; por ello, huían de los campus tradicionales con disposición de usos en pabellones aislados, tratando de aglutinar relaciones, comunicaciones e instalaciones en edificios compactos.

El edificio se proyectó en una disposición cerrada con patios interiores que permitían iluminar adecuadamente y de manera equilibrada los distintos elementos que componen la planta. La economía buscada con este edificio compacto se deriva de una mayor protección
Fig. 5. Esquema de crecimiento de la Universidad Laboral de Madrid.

Fig. 6. Detalle maqueta para concurso Universidad Laboral de Madrid.
8. Según palabras del propio López Zanón, el general Franco conoció por aquellas fechas el Hospital Ramón y Cajal, que había sido inaugurado en la nochebuena de 1956, proyectado por el arquitecto Marcide, y quiso que la Universidad Laboral de Madrid, un proyecto muy querido para él, fuera de la misma mano que el citado Hospital. Finalmente, por motivos aún confusos, este edificio no se llegó a construir. 


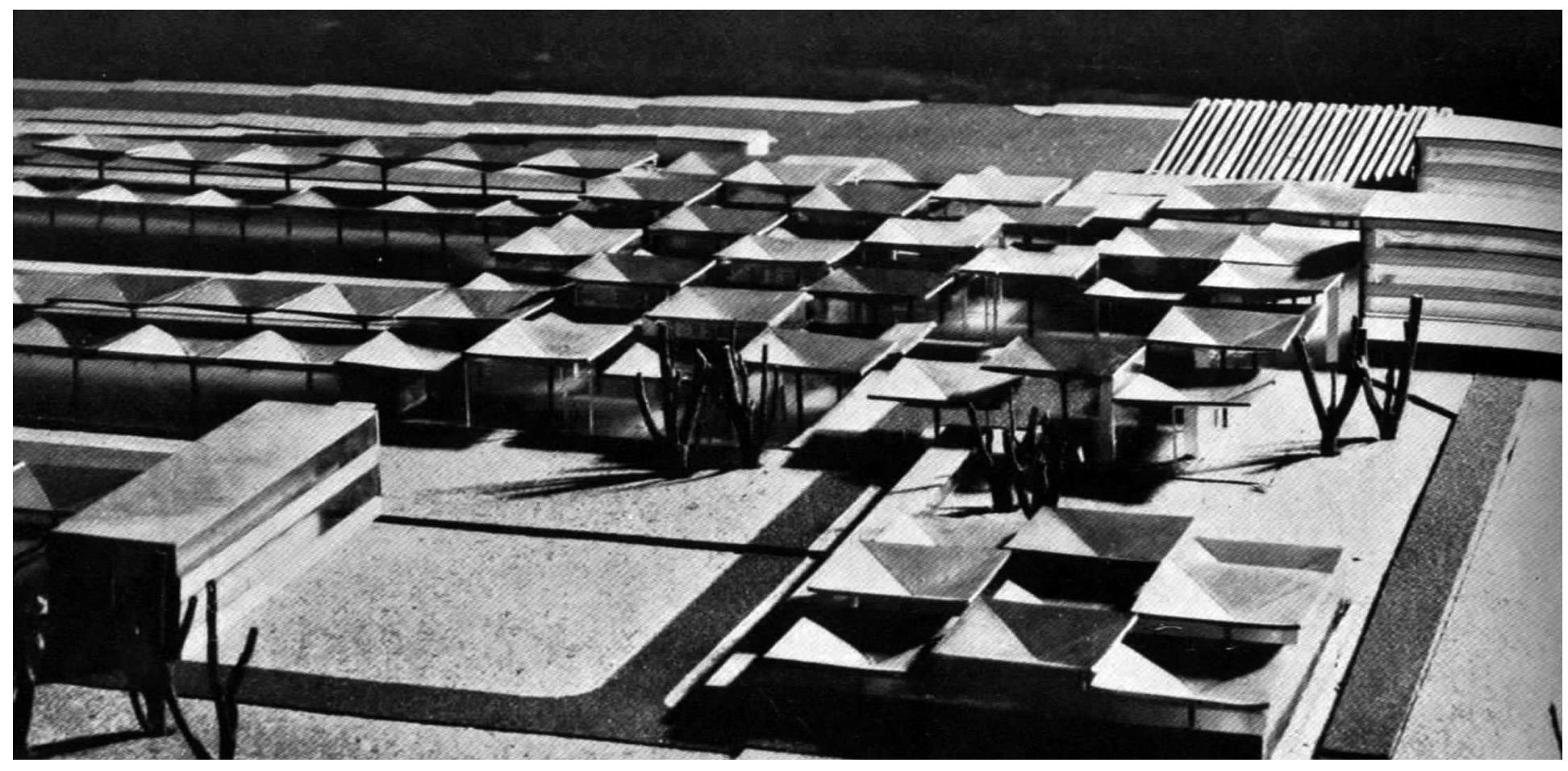

Fig. 7. Escuela Munkegaards. A. Jacobsen.

9. Ciclo de conferencias Lecciones de Arquitectura, pronunciadas por José López Zanón en la Escuela de Arquitectura de la Universidad de Navarra los días 8, 9 y 10 de noviembre de 2011

10. A pesar de las evidentes diferencias formales y funcionales entre ambos edificios, los arquitectos mantienen un indudable interés en conseguir que los espacios de circulación, necesariamente grandes, tuviesen una relación fundamental con la luz, convirtiéndose en verdaderos ejes vertebradotes del proyecto.

11. SOLAGUREN-BELASCOA, F., Arne Jacobsen, aproximación a la obra completa, 1950-1971, Fundación Caja de Arquitectos, Barcelona, 2001, p. 42, "La horizontalidad permite el uso de una trama homogénea en la que se alternan los espacios construidos con los vacíos; estos, a su vez, son subdivididos en el otro sentido por los cinco pasillos de distribución que conducen a las aulas. En este planteamiento homogéneo sólo destaca la sala de actos y el edificio de los talleres situados al final de la cuadrícula". de la intemperie requerida por el severo clima, del ahorro de recorridos, la posibilidad de jerarquizar las actividades, de controlar las funciones y de superponerlas al máximo. Por ello, y aunque dividido en cuatro zonas claramente diferenciadas, funciona como un elemento unitario, tanto en sus circulaciones como en su volumetría.

La zona docente, con su concepto de aulas con patio, se planteó con un carácter transparente y abierto, en ocasiones mediterráneo. Los arquitectos ${ }^{9}$ habían estado trabajando en la idea del módulo desde su proyecto en Coruña, de ahí el módulo clase-patio con el que ensayaron en Huesca, que posteriormente emplearían en la U niversidad L aboral de Cáceres y cuyas plantas comparten indudablemente diferentes el ementos y planteamientos conceptuales. Se plantearon veintisiete aulas, de las que veinte eran para cuarenta alumnos cada una, cuatro para sesenta alumnos y tres para ciento cuatro al umnos.

El model o edificatorio que habían elegido para Coruña, vinculado al agrupamiento rural gallego, se vio desplazado en este caso por la evolución de su teoría acerca de los edificios docentes: si en Coruña L aorga y López Zanón argumentaban que una U niversidad Laboral no era propiamente una U niversidad (planteada como institución educativa que aglutina las diferentes ramas del saber, en busca de una universalidad de los conocimientos), en Huesca parece que los arquitectos se contradicen 0 , al menos, se desdicen, ya que aplican a este edificio (y a Cáceres, con posterioridad) las conclusiones de su reflexión acerca de las bondades de la fusión de usuarios dedicados a las diferentes ramas del saber en un volumen unitario; es, en este sentido, una evolución de su reflexión tipológica y funcional, que pasa por adaptar al gunos de los conceptos empleados en Coruña - como el aula vinculada a un patio privadopero aglutinando los usos en un edificio unitario.

Por ello, el planteamiento de un edificio compacto, fruto de esta evolución de Laorga y López Zanón acerca de las implicaciones del pensamiento universitario, sorprende en un primer momento si se compara programática y volumétricamente con Coruña, pero convence cuando se estudia a fondo la enorme calidad de la solución en planta y la riqueza de sus espacios intersticiales y sus relaciones internas ${ }^{10}$. Se podrían establecer, llegados a este punto, al gunas comparaciones con la escuela M unkegaards (1951-1958) de A rne J acobsen ${ }^{11}$, válidas tanto para Coruña como para Huesca.

El conjunto, a pesar de plantearse en una sola pieza, debía dar respuesta a diferentes usos, tanto en calidad de los espacios como en accesos, modo de utilización y presencia volumétri- 


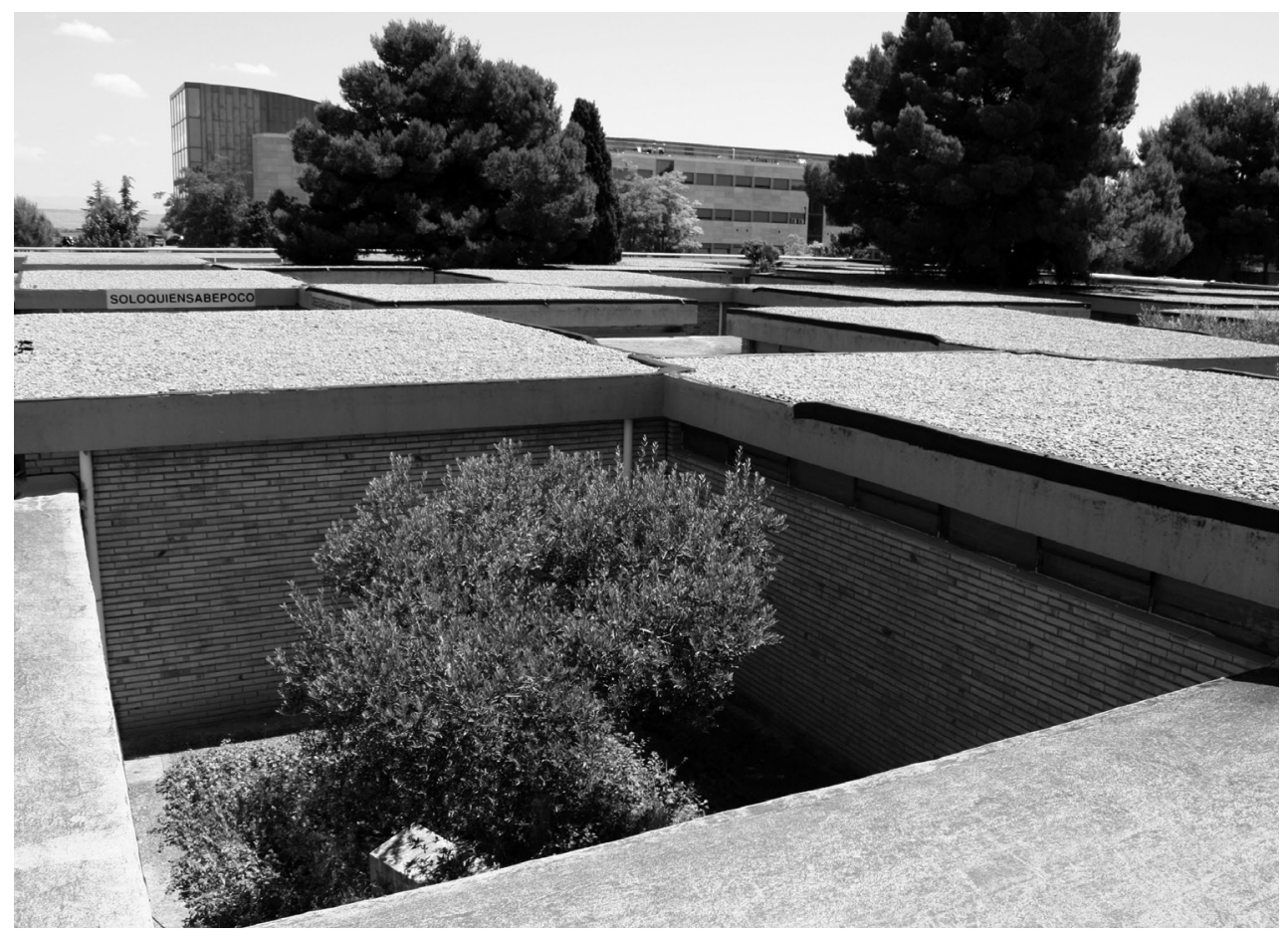

Fig. 8. Aulas-patio de la Universidad Laboral de Huesca.

ca. Con todo ello, un programa de necesidades heterogéneo se resolvió con acierto mediante la disposición de tres órdenes de patios que, además de servir para las obvias funciones de iluminación y ventilación de los espacios servidos, articulaban las plantas, ayudando a comprender las diferentes áreas que las conformaban: en primer lugar, los patios propios de cada aula que, como células, pertenecían a la desagregación mínima del edificio; en segundo lugar, los patios de la zona de administración y de talleres, de una dimensión importante y que posibilitaban una relación directa entre interior y exterior, de manera todavía privativa, del usuario; en tercer lugar, la gran plaza de acceso (no un patio propiamente dicho) y la gran plaza central, como lugares comunes de relación y encuentro entre los diferentes grupos que formaban la comunidad educativa.

La zonificación de espacios ayudaba, por tanto, a establecer de manera clara e inequívoca el orden de relación interna del edificio y, consecuentemente, su sistema de comunicaciones. Al ser un edificio desarrollado fundamental mente en planta baja, todas las relaciones se desarrollaron en horizontal. En este sentido, se pueden detectar tres grandes espacios internos de relación: en primer lugar, el gran acceso principal, zona de relación por excelencia, al rededor de la cual gravitan los usos comunes como el auditorio, la capilla, la zona de administración y dirección y la comunicación con el resto del edificio; en segundo lugar, el gran eje divisor entre la zona de residencias y el resto del edificio, que tiene su simétrico respecto a la gran plaza central para dar acceso a los talleres; por último, el grupo de pasillos en peine para acceso a las aulas, que reciben luz e iluminación natural a través de los patios privativos de cada una de las aulas.

Casi cincuenta años después de su inauguración, la vigencia del edificio de la Universidad L aboral de Huesca (y Cáceres, cuya concepción fue muy semejante a esta) sigue siendo total, mostrando planteamientos completamente válidos en cuanto a su organización en planta, el uso de los materiales, la composición y volumetría pero, por encima de todo, la exquisita utilización del concepto de aula-patio que, sin ser una novedad en la historia de la arquitectura, sí se utilizó con acierto y convicción por parte de los arquitectos de tal modo que la relación entre interior y exterior fue plenamente aprovechada.

Laorga y López Zanón demostraron durante toda su obra y, más concretamente en sus proyectos para las U niversidades $L$ aborales, ser partidarios del vitalismo como motor del proceso creativo, resumido en la siguiente máxima: construir desde dentro hacia fuera; es decir, que la forma, en último término, siguiese a la función. Para ellos, bajo este punto de 
vista, partir de una imagen preconcebida habría sido el mayor error en el que podrían haber caído. Esto queda patente en su propio discurso y en el hecho de que se percibe claramente que el desarrollo de sus concursos y proyectos se parte del programa, llegando al esquema conceptual y, a través de las plantas, se construye una volumetría concreta. Como resultado de este proceso de trabajo, y no como idea generadora de concurso, surgen las imágenes de un modo natural, sin ambigüedades ni contradicciones lo que, sin lugar a dudas, se convierte en fiel reflejo de la voluntad y ambición proyectual de sus creadores.

Pablo Basterra Ederra. Arquitecto por la Universidad de Navarra (2001), compatibiliza el ejercicio liberal de la profesión con su tarea docente como profesor asociado en el Departamento de Proyectos en la misma Universidad (2005-2015). Ha sido profesor encargado de la asignatura de Dibujo Arquitectónico, en primer curso de Arquitectura en la ETSAUN. Su campo de investigación preferente es la Historia de la arquitectura española en la segunda mitad del siglo XX, habiendo participado en diferentes congresos nacionales e internacionales sobre este tema. En mayo de 2015 defendió su tesis doctoral, titulada Arquitectura para una utopía: Universidades Laborales 1952-1976, centrándose en el estudio de las Universidades Laborales de Gijón y Zamora (Luis Moya), Coruña y Huesca (Luis Laorga y José López Zanón), Toledo y Cheste (Fernando Moreno Barberá) y Almería y Ourense (Julio Cano Lasso y Alberto Campo Baeza). 